GRASAS Y ACEITES 69 (1)

January-March 2018, e232

ISSN-L: 0017-3495

https://doi.org/10.3989/gya.0668171

\title{
Cold-pressed pumpkin seed (Cucurbita pepo L.) oils from the central Anatolia region of Turkey: Characterization of phytosterols, squalene, tocols, phenolic acids, carotenoids and fatty acid bioactive compounds
}

\author{
G. Akin ${ }^{\mathrm{a}}$, F.N. Arslan ${ }^{\mathrm{a},}$, S.N. Karuk Elmas ${ }^{\mathrm{a}}$ and I. Yilmaz \\ ${ }^{a}$ Karamanoglu Mehmetbey University, Faculty of Science, Department of Chemistry, 70100, Karaman, Turkey \\ Corresponding author: arslanfatmanur@gmail.com
}

Submitted: 26 June 2017; Accepted: 06 October 2017

SUMMARY: There is a growing interest in cold-pressed oils because they present high contents of bioactive compounds. These oils have the characteristic properties of seeds and are specific products of their regions. The aim of this study was to determine the compositions and contents of fatty acids, phytosterols, squalene, tocols, phenolic acids, carotenoids and phenolic bioactives, and the free radical scavenging as well as antioxidant activities of coldpressed pumpkin (Cucurbita pepo L.) seed oils. Oil samples from raw pumpkin seeds cultivated in four different central Anatolia regions of Turkey were prepared using a laboratory screw-pressing machine. The results indicate that coldpressed pumpkin seed oils (PSO) have excellent quality with high contents of polyunsaturated fatty acids (\%乏PUFAs) (53.60 $\pm 0.06-53.73 \pm 0.05)$, total phytosterols $(782.1 \pm 9.7-805.2 \pm 11.3 \mathrm{mg} / 100 \mathrm{~g}$ oil), squalene $(591.3 \pm 10.6-632.5 \pm 11.4$ $\mathrm{mg} / 100 \mathrm{~g}$ oil $)$, tocols $(97.79 \pm 0.76-94.29 \pm 0.34 \mathrm{mg} / 100 \mathrm{~g}$ oil $)$, phenolic acids $(22.73 \pm 0.41-23.98 \pm 0.46 \mathrm{mg} / 100 \mathrm{~g}$ oil $)$, carotenoids ( $6.95 \pm 0.03-7.60 \pm 0.03 \mathrm{mg} / 100 \mathrm{~g}$ oil), total phenolics $(3.96 \pm 0.13-5.82 \pm 0.15 \mathrm{mg} \mathrm{GAE} / 100 \mathrm{~g})$, free radicalscavenging activity $(5.70 \pm 0.13-7.35 \pm 0.15 \mathrm{mg} \mathrm{GAE} / 100 \mathrm{~g})$ and total antioxidant activity $(26.67 \pm 0.97-38.89 \pm 1.41$ mg GAE/100 g) values. Thus, this study demonstrates that the cold- pressed PSOs from the central Anatolia regions of Turkey are an excellent source of natural bioactive compounds, free of chemical contaminants and nutritious.

KEYWORDS: Antioxidant activity; Bioactive compound; Cold-pressed oil; Cucurbita pepo L.; Phenolic acid; Tocol profile

RESUMEN: Aceites de semillas de calabaza prensados en frío (Cucurbita pepo L.) de la región central de Anatolia en Turquía: Caracterización de fitosteroles, escualeno, tocoles, ácidos fenólicos, carotenoides y compuestos bioactivos de ácidos grasos. Existe un interés creciente en los aceites prensados en frío, ya que presentan altos contenidos de compuestos bioactivos. Estos aceites tienen las propiedades características de las semillas y son productos específicos de las regiones. El objetivo de este estudio fue determinar las composiciones y contenidos de ácidos grasos, fitoesteroles, escualeno, tocoles, ácidos fenólicos, carotenoides y bioactivos fenólicos, la actividad de eliminación de radicales libres, así como las actividades antioxidantes de aceites de semillas de calabaza prensados en frío (Cucurbita pepo L.). Las muestras de aceite de semillas de calabaza cultivadas en cuatro regiones diferentes de Anatolia central de Turquía se prepararon utilizando una máquina de laboratorio de prensado mediante tornillo. Los resultados indican que los aceites de semilla de calabaza prensados en frío (PSO) tienen una excelente calidad, con altos contenidos de ácidos grasos poliinsaturados (\% $\%$ PUFA) $(53,60 \pm 0,06-53,73 \pm 0,05)$, fitoesteroles totales $(782,1 \pm 9,7-805,2 \pm 11,3 \mathrm{mg} / 100 \mathrm{~g}$ de aceite), escualeno (591,3 $\pm 10,6-632,5 \pm 11,4 \mathrm{mg} / 100 \mathrm{~g}$ de aceite), tocols $(97,79 \pm 0,76-94,29 \pm 0,34 \mathrm{mg} / 100 \mathrm{~g}$ de aceite), ácidos fenólicos (22,73 \pm 0,41-23,98 $\pm 0.46 \mathrm{mg} / 100 \mathrm{~g}$ de aceite), carotenoides $(6,95 \pm 0,03-7,60 \pm 0,03 \mathrm{mg} / 100 \mathrm{~g}$ de aceite), fenólico total (3,96 \pm 0,13-5,82 $\pm 0,15 \mathrm{mg}$ GAE / $100 \mathrm{~g})$, actividad de eliminación de radicales libres (5,70 \pm $0,13-7,35 \pm 0,15 \mathrm{mg} \mathrm{GAE} / 100 \mathrm{~g})$ y la actividad antioxidante total $(26,67 \pm 0,97-38,89 \pm 1,41 \mathrm{mg}$ GAE/100 g) valores. Por lo tanto, el estudio demuestra que los PSO prensados en frío de las regiones centrales de Anatolia de Turquía son una excelente fuente de compuestos bioactivos naturales, químicamente libres de contaminantes y nutritivos.

PALABRAS CLAVE: Aceite prensado en frío; Ácidos fenólico; Actividad antioxidante; Compuestos bioactivos; Cucurbita pepo L.; Perfil de Tocoles

ORCID ID: Akin G https://orcid.org/0000-0001-7477-3186, Arslan FN https://orcid.org/0000-0002-5748-8268, Karuk Elmas SN https://orcid.org/0000-0002-1661-5902, Yilmaz I https://orcid.org/0000-0002-9447-3065

Citation/Cómo citar este artículo: Akin G, Arslan FN, Karuk Elmas SN, Yilmaz I. 2107. Cold pressed pumpkin seed (Cucurbita pepo L.) oils from the central Anatolia region of Turkey: Characterization of phytosterols, squalene, tocols, phenolic acids, carotenoids and fatty acid bioactive compounds. Grasas Aceites 69 (1), e232. https://doi.org/10.3989/gya.0668171

Copyright: (C2018 CSIC. This is an open-access article distributed under the terms of the Creative Commons Attribution 4.0 International (CC BY 4.0) License. 


\section{INTRODUCTION}

Edible oils have been obtained by different technologies and utilized as food ingredients since ancient times. Recently, consumer interest in nonrefined edible oils has been increasing, due to the growing evidence that among these oils, a special place belongs to so-called "cold pressed oils", which have nutritional and health benefits (Nederal et al., 2014). Cold pressing is one of the oldest oil extraction techniques in which no heat-treatment, refining, solvent extraction, or use of chemicals is included. This extraction technique does not provide as high an extraction yield as other technologies and a large amount of oil cannot be recovered from the oil source. However, it has been emphasized that cold pressing is a highly suitable technology for edible oil production enhanced with bioactive compounds. Cold pressing has a major advantage of minimizing the degradation of nutritive oil bioactives such as phytosterols, tocols, fatty acids, vitamins, carotenoids... etc. The produced oils are also more attractive to consumers in terms of their nutritional and functional properties. Therefore, in recent years cold pressing has become an increasingly popular technique for the production of different seed oils (Jafari et al., 2012).

Nowadays, cold-pressed oil from the seeds of different pumpkin (Cucurbita) varieties is emerging as a commercial product in markets. Cold-pressed pumpkin seed oil (PSO) is obtained by continuous mechanical pressing of untreated, dried seeds at temperatures not exceeding $50{ }^{\circ} \mathrm{C}$ (Rabrenovic et al., 2014; Nederal et al., 2012). Cold-pressed PSOs as a rich source of bioactive components have been commonly used as edible oil or a potential nutraceutical product. It has been related to potential health benefits such as the prevention of prostate cancer, improvement of hypercholesterolemia, arthritis and bladder compliance, retardation of the hypertension, decreasing of bladder and urethral pressure, and alleviation of diabetes, lowering the levels of cancers, and possessing high-quality antioxidant potential (Fruhwirth et al., 2003; Jiao et al., 2014; Reziget al., 2012). Due to their specific and positive health effects, there are several studies on pumpkin seed cultivars in different countries which assess the content of bioactive compounds. Vujasinovic et al., (2010) reported the sensory properties, quality characteristics and oxidative stabilities of screw-pressed pumpkin (Cucurbita pepo L.) seed oils. The contents of essential fatty acids in the oil samples were determined as $30.35-42.07 \%$ for oleic and $43.68-52.15 \%$ for linoleic acid, and $0.16-0.26 \%$ for linolenic acid. Kulaitiene et al., (2016) reported the characteristics of bioactive compounds and antioxidant properties of the PSOs obtained from different varieties. The study stated that oleic $(22.10-36.20 \%)$ and linoleic $(42.00-59.20 \%)$ unsaturated fatty acids are dominant, and $\gamma$-tocopherol $(6.14-40.70 \mathrm{mg} / 100 \mathrm{~g}$ oil) was identified as a major tocol isomer. The seeds of pumpkin varieties also exhibit high antioxidant activity. Andjelkovic et al., (2010) reported the concentration of phenolic compounds and that phenolic content ranged from 2.471 to $5.093 \mathrm{mg} \mathrm{GAE} / 100$ g. Nederal et al., (2014) concluded that PSOs contain an essential $\omega-6$ fatty acid (18:2, linoleic acid) in the range of $41.51 \%$ to $51.55 \%$ of total polyunsaturated fatty acids (PUFA).Also, PSO has a high level of $\gamma$-tocopherols, phytosterols, and phospholipid bioactive compounds (Jiao et al., 2014; Rezig et al., 2012; Andjelkovic et al., 2010)

The genetic factors, extraction technique, cultivation, climate, production and storage conditions of seed oils are critical factors for the content of bioactive compounds (Nawirska-Olszanska et al., 2013). To the best of our knowledge, there is no research in the literature on the assessment of different pumpkin cultivars from the central Anatolia regions of Turkey to determine their potential for commercial and industrial applications. Therefore, the aim of this research was to determine the contents and profile of fatty acids, phytosterols, squalene, tocols, phenolic acids, carotenoids and total phenolic bioactives, and the free radical scavenging as well as antioxidant activities of the cold-pressed pumpkin (Cucurbita pepo L.) seed oils, cultivated in different central Anatolia regions of Turkey.

\section{MATERIALS AND METHODS}

\subsection{Materials, reagents and raw pumpkin seed samples}

A fatty acid methyl ester mix C14-C22 (wt. \% varied conc., ampule of $100 \mathrm{mg}$ ), DL- $\alpha$-tocopherol acetate $(\geq 96 \%),(+)-\gamma$-tocopherol $(\geq 96 \%)$, rac- $\beta$ tocopherol, $\delta$-tocopherol and tocotrienol $(\alpha-, \beta-$, $\gamma$-and $\delta$-) analytical standards were purchased from Sigma-Aldrich (St. Louis, USA). All chemicals, reagents and solvents used were of analytical or HPLC grade and obtained from VWR International (Poole, UK), Sigma-Aldrich (St. Louis, MO, USA) or Merck (Darmstadt, Germany) companies. Deionized water $(>18 \mathrm{M} \Omega . \mathrm{cm})$ was obtained from a Milli-Q system (Millipore, Brussels, Belgium). Standards for sterol (spinasterol, $\beta$-sitosterol, $\Delta 7,22,25$-stigmastatrienol, $\Delta 7,25$-stigmastadienol, $\Delta 7$-stigmasterol, $\Delta 7$-avenasterol), phenolic acid (arbutin, gallic acid, 5-hydroxymethyl furfural, protocatechuic acid, procyanidin, 4-hydroxybenzoic acid, catechin, chlorogenic acid, procyanidin B2, caffeic acid, syringic acid, vanillic acid, $p$-coumaric acid, ferulic acid, sinapic acid, quercetin-3-rutinoside, quercetin-3-galactoside, quercetin-3-glucoside, quercetin-3-xyloside, quercetin-3-arabinoside, quercetin-3-rhamnoside, isorhamnetin-3-glocoside, phloridzin, cinnamic acid, quercitin, phloretin) 
and carotenoid bioactives, and silylating agents (pyridine, hexamethyldisilazane and chlorotrimethylsilane) were obtained from Sigma-Aldrich (St. Louis, USA). Four different cold-pressed pumpkin seed (Cucurbita pepo L.) oil samples were studied to determine their bioactive compound contents. Commercially available pumpkin seeds (Cucurbita реро L.) harvested in the regions of central Anatolia of Turkey (Celtik-Konya, Cumra-Konya, Iceri Cumra-Konya and Polatli-Ankara), were purchased from local suppliers. Raw pumpkin seeds were of domestic origin and harvested in mid-autumn of 2015, and used for screw-pressing. The raw pumpkin seeds were stored in closed bags in the dark at 4 ${ }^{\circ} \mathrm{C}$, until the extraction process.

\subsection{Cold-press extraction procedure}

Oils were extracted from sampled seeds according to the screw-pressing process. This pressing is performed by directly pressing raw/dried seeds onto a continuous screw press at low temperatures. A laboratory-scale screw press machine $\left(15 \mathrm{~kg}\right.$ seed. $\mathrm{h}^{-1}$ capacity, single head, $2 \mathrm{hp}, 1.5 \mathrm{kw}$ power) in our laboratory was used for the pressing of seed samples. $40 \mathrm{rpm}$ screw rotation speeds and $40{ }^{\circ} \mathrm{C} \pm 0.05$ temperatures were selected as process parameters. The temperature of the extracted oil was measured throughout the experiments with a digital thermometer. For screw-pressing, $10 \mathrm{~kg}$ of Celtik-Konya, $7 \mathrm{~kg}$ of Cumra-Konya, $10 \mathrm{~kg}$ of Iceri Cumra-Konya and $8 \mathrm{~kg}$ of Polatli-Ankara region raw pumpkin seed samples were used. At the end of the cold-pressing process, the oil and meal with oily cake were collected, and then the oil was filtered to remove suspended materials. After one day sedimentation in closed dark bottles at temperatures below $15^{\circ} \mathrm{C}$, the extracted oil was separated from the sediment by decantation, and then it was centrifuged in a centrifuge system (Sigma 2-16K, Germany) for 20 min at $10{ }^{\circ} \mathrm{C}$. The cold-pressed oils were stored in dark green glass bottles. The bottles were kept in the refrigerator at $4{ }^{\circ} \mathrm{C}$, until the analysis.

\subsection{Determination of the fatty acid composition by GC-FID}

The fatty acid composition analysis was performed in an Agilent $7890 \mathrm{~A}$ gas chromatography system equipped with a flame ionization detector (FID) (Agilent Tech. Inc., USA). Fatty acid methyl esters (FAMEs) of the oil samples were prepared according to the method described by Arslan et al., (2017) with a $2 \mathrm{~N}$ potassium hydroxide solution in methanol. Briefly, $0.1 \mathrm{~g}$ of the PSO was weighed into a centrifuge tube and dissolved in $10 \mathrm{~mL}$ of hexane. Then, $0.1 \mathrm{~mL}$ of $2 \mathrm{~N}$ potassium hydroxide solution was added and the tube was vigorously shaken for $60 \mathrm{~s}$. Then, the mixture was subjected to centrifugation for $5 \mathrm{~min}$, at $2000 \mathrm{rpm}$. In the last stage, the upper layer was moved to a vial for analysis. The operating conditions for FAME analysis were carried out according to Gu et al., (2011) with a few modifications. Separations were performed on a HP-5MS $(30 \mathrm{~m} \times 0.25 \mathrm{~mm} \times 0.25 \mu \mathrm{m}$, Agilent $)$ capillary column. The injection volume was $1 \mu \mathrm{L}$ with a split ratio of 100:1. The inlet temperature was $230^{\circ} \mathrm{C}$. The oven temperature program was started at $60^{\circ} \mathrm{C}$, then linearly increased to $175^{\circ} \mathrm{C}\left(15^{\circ} \mathrm{C} / \mathrm{min}\right)$ and then linearly increased to $240{ }^{\circ} \mathrm{C}\left(2{ }^{\circ} \mathrm{C} / \mathrm{min}\right)$, and kept at this temperature for $10 \mathrm{~min}$. Fatty acids were identified based on the retention times of a FAME mix C14:0C22:0 standard injected under the proposed method conditions and expressed as $\mathrm{g} / 100 \mathrm{~g}$ of totally fatty acids. The data were processed with the aid of Agilent ChemStation 2001-2010 data processor.

\subsection{Determination of phytosterols and squalene by GC-MS}

Phytosterol and squalene determination was performed according to the method described by Rabrenovic et al., (2014). The phytosterol derivatives were analyzed using an Agilent $7890 \mathrm{~N}$ gas chromatography system equipped with FID and 5975C MSD detector systems (Agilent Tech. Inc., USA). $7.5 \mathrm{~mL}$ of a cholesterol solution as an internal standard, with a concentration of $1.33 \mathrm{mg} / \mathrm{mL}$ prepared with methylene chloride, were put into $4.5 \mathrm{~g}$ of sample. After the evaporation of the solvent, the sample was saponified with $20 \mathrm{~mL}$ of a 6 $\mathrm{M} \mathrm{KOH}$ aqueous solution. The blend was diluted with $30 \mathrm{~mL}$ of ethanol (with up to $50 \mathrm{~mL} / \mathrm{L}$ diethyl ether), and then it was refluxed for $90 \mathrm{~min}$ at $70^{\circ} \mathrm{C}$. After saponification, $30 \mathrm{~mL}$ of water were added, and the unsaponifiables were extracted three times with $45 \mathrm{~mL}$ of petroleum ether and $45 \mathrm{~mL}$ of diethyl ether, respectively. The extracts were merged, washed three times with $20 \mathrm{~mL}$ of $0.5 \mathrm{M} \mathrm{KOH}$ and $20 \mathrm{~mL}$ of $50 \mathrm{mg} / \mathrm{L} \mathrm{NaCl}$ until the neutral $\mathrm{pH}$ of washing water. The organic fraction was dried with $\mathrm{Na}_{2} \mathrm{SO}_{4}$ and filtrated. The phytosterol derivatives were prepared by adding $1.5 \mathrm{~mL}$ of drypyridine, $0.2 \mathrm{~mL}$ hexamethyldisilazane, and $0.1 \mathrm{~mL}$ chlorotrimethylsilane in a vial and heated to $80{ }^{\circ} \mathrm{C}$ for 30 min. The derivatized parts were transferred into a vial and after derivatization they were analyzed by GC-MS within $6 \mathrm{~h}$. A mixture of derivized phytosterol standard solutions was also prepared by the same procedure.

GC-MS separations were performed on a HP-5MS $(30 \mathrm{~m} \times 0.25 \mathrm{~mm} \times 0.25 \mu \mathrm{m}$, Agilent $)$ capillary GC column. The flow rate of carrier gas (helium) was $1.5 \mathrm{~mL} / \mathrm{min}$ and the injected sample volume was of $1 \mu \mathrm{L}$ in the splitless mode. The temperature program was as follows: a gradient of $3{ }^{\circ} \mathrm{C} / \mathrm{min}$ from $60{ }^{\circ} \mathrm{C}$ to $300^{\circ} \mathrm{C}$, and held at this temperature for 10 min. MS data were obtained in the EI mode with a scan range of $30 \mathrm{e} 550 \mathrm{~m} / \mathrm{z}$; the source temperature 
was $230{ }^{\circ} \mathrm{C}$, quadrupole temperature was $150{ }^{\circ} \mathrm{C}$ and hold-up time was 3 min.

\subsection{Determination of the tocol profile by HPLC- FLD}

The tocol (tocopherol and tocotrienol) profiles of the PSOs were identified using a normal-phase liquid chromatographic (NP-HPLC) method (Arslan et al., 2016). An Agilent 1200 series HPLC system (Agilent Technologies Inc., USA) was equipped with a G1321C model fluorescence detector (FLD) and G1316A model column compartment set at 20 ${ }^{\circ} \mathrm{C}$. Separation was achieved on a LiChrospher $100 \AA$ diol column $(250 \times 4.0 \mathrm{~mm}$ id., $5 \mu \mathrm{m}$, Teknokroma, Barcelona) equipped with a guard column $(75 \times 4.0$ $\mathrm{mm}$ i.d.,5 $5 \mathrm{~m}$, Teknokroma, Barcelona). The data were recorded using an Agilent ChemStation 2001-2010 data processor. Before HPLC analysis, one gram of oil was weighed, then dissolved in $10 \mathrm{~mL}$ hexane, centrifuged and filtered through a PTFE syringe filter $(0.45 \mathrm{~mm}) .5 \mu \mathrm{L}$ of the sample were injected and a mixture of hexane:2-propanol (99.4:0.6, v/v) was used as a mobile phase under isocratic conditions with a flow rate of $0.7 \mathrm{~mL} \cdot \mathrm{min}^{-1}$. Detection of tocol isomers was performed at $\lambda_{\text {exc }}=$ $295 \mathrm{~nm}$ and $\lambda_{\mathrm{em}}=330 \mathrm{~nm}$ by FLD. Commercial standards of all of the tocols were used for calibration, and curves ranging from 0.1 to $3.0 \mathrm{mg} \cdot \mathrm{mL}^{-1}$ were linear for all tocols $\left(\mathrm{R}^{2}>0.99\right)$. Contents of each tocol were expressed in $\mathrm{mg} .100 \mathrm{~g}^{-1}$ oil.

\subsection{Determination of phenolic acid profile by HPLC-MS/MS}

\subsubsection{Phenolic acid extraction.}

The phenolic acids were extracted according to the method of Mateos et al., (2001) with some modifications. $2.500 \pm 0.001 \mathrm{~g}$ of PSO sample were weighed, and dissolved in $6 \mathrm{~mL}$ of hexane. A diolbonded phase cartridge column (Grace; ps $50 \mathrm{~mm}$, pore size $60 \AA$, not end-capped, $500 \mathrm{mg}$ bed size and $4 \mathrm{~mL}$ column size) was conditioned by e $6 \mathrm{~mL}$ of methanol and $6 \mathrm{~mL}$ of hexane, respectively. The oil solution was applied to the cartridge, and the solvent was pulled through by releasing the sample onto the column phase. The sample vessel was washed with 6 $\mathrm{mL}$ portions of hexane, followed by elution of the solvent which was then discarded. After that, the sample vessel was washed with $4 \mathrm{~mL}$ of hexane/ethyl acetate $(90: 10, \mathrm{v} / \mathrm{v})$, which were removed from the cartridge and discarded. Finally, the phenolic compounds were eluted from the sorbent with $10 \mathrm{~mL}$ methanol, and the solvent was evaporated under vacuum. The residue was extracted with $500 \mu \mathrm{L}$ of methanol: water $(50: 50, \mathrm{v} / \mathrm{v})$ at $40{ }^{\circ} \mathrm{C}$. An aliquot of the final extract $(20 \mu \mathrm{L})$ was filtered through a
PTFE syringe filter $(0.45 \mathrm{~mm})$ and was injected into the HPLC system.

\subsubsection{Chromatographic analysis of phenolic acids.}

A Chromatographic analysis was performed using an Agilent HPLC system equipped with a G4212B model photodiode array detector (DAD) and the column outlet was coupled to an Agilent MSD Ion Trap XCT mass spectrometer equipped with an ESI ion source. A Lichrospher 100RP-18 column $(250 \mathrm{~mm} \times 4.0 \mathrm{~mm}, 5 \mu \mathrm{m})$, maintained at $40{ }^{\circ} \mathrm{C}$ was used. The injection was $10 \mu \mathrm{L}$ of the extract $(20 \mu \mathrm{L})$ obtained from the previous step. Elution was performed at a flow rate of $0.4 \mathrm{~mL} /$ min, using solvent A ( $1 \% \mathrm{HAc}$ in ultra-pure water) and solvent $\mathrm{B}(1 \% \mathrm{HAc}$ in methanol) as the mobile phase. The solvent gradient changed according to the following conditions: from $10 \%$ to $20 \%$ solvent $\mathrm{B}$ in $4 \mathrm{~min}$, and a second step gradient from $20 \%$ to $100 \%$ solvent B in $20 \mathrm{~min}$. Then, it was kept for 6 min with $100 \%$ solvent $\mathrm{B}$, finally, the elution was obtained from $100 \%$ to $20 \%$ solvent B for 6 min (Rezig et al., 2012). A stock solution of standards at a concentration $1 \mu \mathrm{g} / \mu \mathrm{L}$ each was prepared and the standards were injected into the system at various concentrations for calibration. Detection of the individual compounds was achieved by comparing retention time and SRM analyses of the sample peaks with that of the authorized pure individual standards. The parameters were used throughout the MS; the capillary voltage was set to $1.6 \mathrm{kV}$, the drying temperature to $350{ }^{\circ} \mathrm{C}$, the nebulizer pressure to $40 \mathrm{psi}$, and the drying gas flow to $10 \mathrm{~L} / \mathrm{min}$. The maximum accumulation time was $50 \mathrm{~ms}$, and the scan speed was 26,000 $\mathrm{m} \mathrm{Z}^{-1} \mathrm{~s}^{-1}$ even as the fragmentation moment was $30 \mathrm{~ms}$. Phenolic compounds were identified using a combination of HPLC with a DAD and ESILC-MS detection on the basis of their ultraviolet spectra at $280 \mathrm{~nm}$, mass spectra and by comparing the spectra with those of obtainable authentic standards (Rezig et al.,2012).

\subsection{Determination of of carotenoid composition by HPLC-DAD-ESI/MS/MS}

The carotenoid composition analysis was performed according to a previously described method with some modifications (Parry et al., 2006). One $\mathrm{mL}$ of PSO was dissolved in $160 \mathrm{~mL}$ of methanol:tetrahydrofuran (THF) $(50: 50, \mathrm{v} / \mathrm{v})$, and the carotenoid composition was determined using a HPLC-DAD-ESI/MS/MS (high performance liquid chromatography-diode array detector/ electrospray ionization/ tandem mass spectrometry) system. An Agilent 1100 HPLC system (Agilent Tech. Inc., USA) and TSQ Quantumtandem mass spectrometry (Thermo-Finnigan, San Jose, CA) was equipped with 
an ESI interface system and used for the analyses of $\beta$-carotene, lutein, cryptoxanthin, and zeaxanthin. The separations were performed using a Zorbax-SB C18 HPLC column $(50 \times 1.0 \mathrm{~mm}$ i.d., $3.5 \mu \mathrm{m})$ (Agilent Tech. Inc., USA). A mobile phase of solvent A (ultrapure water) and solvent B [methanol: acetonitrile:2propanol $(54: 44: 2, \mathrm{v} / \mathrm{v} / \mathrm{v})]$ was used with a gradient program as follows; the gradient was linear from $50 \%$ to $99 \%$ of solvent B, and the flow rate was increased from 0.2 to $0.27 \mathrm{~mL} / \mathrm{min}$ in the first $10 \mathrm{~min}$, and $99 \%$ of solvent $\mathrm{B}$ and flow rate of $0.27 \mathrm{~mL} / \mathrm{min}$ for 10 min. Prior to the next injection, the column was reequilibrated for $10 \mathrm{~min}$ with $50 \%$ of solvent $\mathrm{B}$. The quantification of carotenoids was determined using the total ion counts compared to external standards of the individual carotenoids. The wavelength of DAD detection was set at $440 \mathrm{~nm}$. The identification of carotenoids was achieved by comparing the retention time and SRM analysis of the sample peaks with that of the commercial carotenoid standards. The TSQ Quantum was operated in the positive-ion mode under the following conditions: nitrogen (>99.7\%) was used for sheath gas and auxiliary gas at pressures of 30 psi and 5 units, respectively. The temperature of the heated capillary was kept at $300^{\circ} \mathrm{C}$, and the spray voltage of ESI was set at $4.5 \mathrm{kV}$. A collision-induced dissociation (CID) was performed using argon as the collision gas at the pressure regulated to more than $1.0 \mathrm{mTorr}$, and the applied collision offset energy was set to $-45 \mathrm{eV}$.

\subsection{Determination of the total phenolic compounds, free radical scavenging activity and antioxidant activity}

Total phenolic compounds (TPCs) were extracted from the cold-pressed PSOs according to the method proposed by Feng-Lin et al., (2010). Briefly, $200 \mu \mathrm{L}$ of the extract obtained from the oil sample and gallic acid (GA) standards (concentration range between 0.05 to $3 \mathrm{mg} \mathrm{GAE}$ ), were transferred into centrifuge tubes. Then, $1 \mathrm{~mL}$ of the Folin-Ciocalteau (FC) reagent and $2 \mathrm{~mL}$ of sodium carbonate $(7.5 \%, \mathrm{w} / \mathrm{v})$ were added, diluted with ultra-pure water to $7 \mathrm{~mL}$ and mixed thoroughly. After shaking, the mixtures were then allowed to stand for 2 hours in the dark before measuring the absorbance in Lambda-25 UV-Vis spectrophotometer (PerkinElmer Inc., Waltham, Massachusetts, U.S.A.) at $765 \mathrm{~nm}$. The measurements were performed in triplicate and the results were expressed as milligrams of gallic acid equivalents (GAEs) per 100 grams of sample. The contents of TPCs in the studied oils is calculated and reported by using calibration graph.

The radical scavenging activity of PSO extract was determined according to the method described by (Molyneux, 2004). In brief, $500 \mu \mathrm{L}$ of the extract obtained from the oil sample and GA standards (0.02-0.14 mg GAE) were transferred into a centrifuge tubes. Then, $3 \mathrm{~mL}$ of $6 \times 10^{-5} \mathrm{M}$ solution of 2,2-diphenyl-1-picrylhydrazyl (DPPH) were added and mixed thoroughly. The absorbance at $517 \mathrm{~nm}$ was measured after reaction at room temperature in the dark for $30 \mathrm{~min}$. A control sample, without oil, was prepared and measured daily. The DPPH' concentration in the reaction medium was calculated from the following calibration curve, determined by the linear regression:

$$
\mathrm{A}_{517}=0.1154 .\left[\mathrm{DPPH}^{\prime}\right]+0.0231\left(R^{2}=0.9933\right)
$$

The radical scavenging activity toward DPPH' was expressed as the \% reduction in DPPH' concentration by the constituents of the oils:

$$
\%[\mathrm{DPPH}]_{\mathrm{red}}=100 \mathrm{x}\left(1-[\mathrm{DPPH}]_{30} /[\mathrm{DPPH}]_{0}\right)
$$

where $\left[\mathrm{DPPH}^{\prime}\right]_{0}$ and $\left[\mathrm{DPPH}^{\prime}\right]_{30}$ were the concentrations of DPPH' in the control sample $(t=0)$ and in the test mixture after $30 \mathrm{~min}$ reaction, respectively (Molyneux, 2004).

In last stage the antioxidant activities of the oil samples were determined according to the method of (Prieto et al., 1999). $300 \mu \mathrm{L}$ of the extract obtained from the oil sample and GA standards $(0.2-1.0 \mathrm{mg}$ GAE), were transferred into centrifuge tubes. Three $\mathrm{mL}$ of reagent solution (mixture of $25 \mathrm{~mL} 0.6 \mathrm{M}$ $\mathrm{H}_{2} \mathrm{SO}_{4}, 25 \mathrm{~mL} 28 \mathrm{mM} \mathrm{Na} \mathrm{HPO}_{4} \cdot 12 \mathrm{H}_{2} \mathrm{O}$ and $25 \mathrm{~mL}$ $4 \mathrm{mM}$ ammonium molybdate) were added. The tubes were incubated at $95^{\circ} \mathrm{C}$ for $90 \mathrm{~min}$. After the mixtures had cooled to room temperature, the absorbance was measured at $695 \mathrm{~nm}$. All analyses were performed in triplicate and the results were expressed as milligrams of GAEs per 100 grams of sample.

\subsection{Statistical analysis}

All analyses were carried out in triplicate and data were expressed as the mean \pm standard deviation. All statistical analyses were performed by means of Excel (Microsoft, 2007) and OriginPro8 (OriginLab, USA) databases.

\section{RESULTS AND DISCUSSION}

\subsection{Fatty acid profiles}

Table 1 presents an overview of the profile and content of fatty acids in the cold-pressed PSO samples. As can be seen in Table 1, the studied PSOs belong to the oleic-linoleic acid type of oil. A total of fourteen cis fatty acids and three trans fatty acids (TFA) in PSO was determined. Fourteen main components; seven saturated fatty acids (SFA), four monounsaturated fatty acids (MUFAs) and three polyunsaturated fatty acids (PUFAs) were identified. The main fatty acids in the studied oils were identified in the order of; linoleic (C18:2), oleic (C18:1), palmitic (C16:0), 
and stearic acid (C18:0). The content of polyunsaturated linoleic acid ranged from $53.19 \pm 0.04 \%$ to $53.27 \pm 0.04 \%$ and was followed by oleic acid which was also present in high contents varying from $27.52 \pm 0.02 \%$ up to $27.59 \pm 0.02 \%$. As reported in previous studies, the high content of linoleic acid is an important nutritional aspect of oil because it is an essential fatty acid for humans and it is involved in the building of cellular membranes, vitamin $\mathrm{D}$, and a variety of hormones (Jiao et al., 2014). The presence of high amounts of linoleic acid also suggested that the analyzed PSOs could be used as a good source of essential fatty acids. High oleic acid contents, detected in all the analyzed oil samples, is also favorable from a cardio-protective and nutritional viewpoint (Fruhwirth et al., 2007).

In all the pumpkin seed oils, palmitic and stearic acids were detected in relatively high amounts ranging from $11.90 \pm 0.01 \%$ to $11.99 \pm 0.01 \%$ and $5.26 \pm 0.01 \%$ to $5.29 \pm 0.01 \%$, respectively. Trace amount of the fatty acids were also identified and these data are similar to those reported by Kostadinovic Velickovska et al., 2015. On the other hand, there are insignificant differences in fatty acid profiles between these results and those reported by Nederal et al., (2014). The differences in profile and amount of certain fatty acids depended on the origin of specific pumpkin (Cucurbita pepo L.) seed oil cultivars, climatic conditions, and post-harvest management (Rabrenovic et al., 2014).

The nutritional values of the studied PSOs were also calculated by their total MUFA (IMUFA), total PUFA ( 2 PUFAs) and total SFA (LSFA) contents (Jiao et al., 2014; Rezig et al., 2012). To the best of our knowledge, a higher intake of MUFAs may emerge as health-promoting food choices on the basis of both cardiovascular benefits and their capacity to decrease the risk of opportunistic diseases. For this reason, the vegetable oil industry has focused attention on vegetable oils with high oleic FAs or MUFAs (Jafari et al., 2012). Herein, the detected amounts of LMUFA ranged from $27.77 \pm 0.04 \%$ to $27.86 \pm 0.05 \%$ (Table 1 ). PUFAs are more susceptible to oxidation reactions, while SFAs are more stable, so the ratio of $\Sigma \mathrm{PUFA} / \mathrm{SF} A$ is generally defined as the best indicator for verifying the degree of oil deterioration and the high ratios signified that the samples were nutritionally valuable. ¿PUFA/ $/$ SFA values have also favorable nutritional implications and a positive physiological effect in the

TABLE 1. Fatty acid profile of the cold-pressed pumpkin seed (Cucurbita pepo L.) oils, g/100 g of totally fatty acids.

\begin{tabular}{|c|c|c|c|c|}
\hline Fatty acids & Celtik PSO -Konya & Cumra PSO -Konya & I. Cumra PSO -Konya & Polatlı PSO -Ankara \\
\hline 14:0 (myristic acid) & $0.08 \pm 0.01$ & $0.05 \pm 0.001$ & $0.07 \pm 0.002$ & $0.06 \pm 0.002$ \\
\hline 16:0 (palmitic acid) & $11.95 \pm 0.01$ & $11.99 \pm 0.01$ & $11.90 \pm 0.01$ & $11.97 \pm 0.01$ \\
\hline 16:1 trans & $0.01 \pm 0.001$ & $0.02 \pm 0.001$ & $0.01 \pm 0.001$ & $0.01 \pm 0.001$ \\
\hline 16:1 (palmitoleic acid) & $0.11 \pm 0.01$ & $0.10 \pm 0.01$ & $0.14 \pm 0.01$ & $0.14 \pm 0.01$ \\
\hline 17:0 (heptadecanoic acid) & $0.04 \pm 0.001$ & $0.01 \pm 0.001$ & $0.02 \pm 0.001$ & $0.03 \pm 0.001$ \\
\hline 17:1 (heptadecanoleic acid) & $0.03 \pm 0.001$ & $0.04 \pm 0.002$ & $0.01 \pm 0.001$ & $0.02 \pm 0.001$ \\
\hline 18:0 (stearic acid) & $5.26 \pm 0.01$ & $5.29 \pm 0.01$ & $5.27 \pm 0.012$ & $5.28 \pm 0.01$ \\
\hline 18:1 ( $\left.\omega^{9}\right)$ (oleic acid) & $27.55 \pm 0.02$ & $27.59 \pm 0.02$ & $27.52 \pm 0.02$ & $27.56 \pm 0.02$ \\
\hline 18:2 trans & $0.01 \pm 0.001$ & $0.01 \pm 0.001$ & $0.01 \pm 0.001$ & $0.010 \pm 0.001$ \\
\hline 18:2 ( $\omega 6)$ (linoleic acid) & $53.21 \pm 0.03$ & $53.25 \pm 0.04$ & $53.27 \pm 0.04$ & $53.19 \pm 0.04$ \\
\hline 18:3 trans & $0.35 \pm 0.01$ & $0.37 \pm 0.01$ & $0.31 \pm 0.01$ & $0.34 \pm 0.01$ \\
\hline 18:3 ( $\omega 3)$ (linolenic acid) & $0.40 \pm 0.01$ & $0.42 \pm 0.01$ & $0.44 \pm 0.01$ & $0.39 \pm 0.01$ \\
\hline 20:1 (eicosenoic acid) & $0.11 \pm 0.01$ & $0.10 \pm 0.01$ & $0.10 \pm 0.01$ & $0.14 \pm 0.01$ \\
\hline 20:2 (eicosadienoic acid) & $0.02 \pm 0.001$ & $0.01 \pm 0.001$ & $0.02 \pm 0.001$ & $0.02 \pm 0.001$ \\
\hline 22:0 (behenic acid) & $0.10 \pm 0.01$ & $0.13 \pm 0.01$ & $0.11 \pm 0.01$ & $0.14 \pm 0.01$ \\
\hline 23:0 (tricosylic acid) & $0.06 \pm 0.003$ & $0.04 \pm 0.001$ & $0.05 \pm 0.003$ & $0.04 \pm 0.002$ \\
\hline 24:0 (lignoceric acid) & $0.08 \pm 0.002$ & $0.07 \pm 0.002$ & $0.07 \pm 0.003$ & $0.09 \pm 0.004$ \\
\hline ESFA & $17.57 \pm 0.04$ & $17.58 \pm 0.03$ & $17.49 \pm 0.02$ & $17.61 \pm 0.03$ \\
\hline EMUFA & $27.80 \pm 0.03$ & $27.83 \pm 0.02$ & $27.77 \pm 0.04$ & $27.86 \pm 0.05$ \\
\hline$\Sigma$ PUFA & $53.63 \pm 0.05$ & $53.68 \pm 0.06$ & $53.73 \pm 0.05$ & $53.60 \pm 0.06$ \\
\hline trans FAs & $0.37 \pm 0.01$ & $0.40 \pm 0.01$ & $0.33 \pm 0.01$ & $0.36 \pm 0.01$ \\
\hline
\end{tabular}

Results are reported as mean value \pm standard deviation of three replicate analyses $(n=3)$

Abbreviations: nd; not determined, SFA; saturated fatty acids, MUFA; mono unsaturated fatty acids, PUFA; polyunsaturated fatty acids, $\omega$; omega, PSO; pumpkin seed oil. 
prevention of both heart and cancer diseases (Arslan et al., 2017; Omah et al., 2000). Herein, the detected amounts of $\Sigma$ PUFA ranged from $53.60 \pm 0.06 \%$ to $53.73 \pm 0.05 \%$, and $\Sigma$ SFA ranged from $17.49 \pm 0.02 \%$ to $17.61 \pm 0.03 \%$ (Table 1 ). The detected ratios of $\Sigma$ PUFA/ $\Sigma$ SFA ranged from $3.05 \pm 0.05,3.05 \pm 0.05$, $3.07 \pm 0.04$, and $3.04 \pm 0.05$, respectively. Trans fatty acid contents were also detected and reported as $0.37 \pm 0.01 \%, 0.40 \pm 0.01 \%, 0.33 \pm 0.01 \%$ and 0.36 $\pm 0.01 \%$ for the PSO samples of Celtik-Konya, Cumra-Konya, Iceri Cumra-Konya and PolatliAnkara, respectively. As expected, cold-pressed PSOs contain much less TFAs on average then refined seed oils (Jafari et al., 2012). Therefore, the fatty acid profiles of PSO can be an indicator of its stability and nutritional quality.

\subsection{Phytosterols and squalene profiles}

Phytosterols are of interest due to their cholesterol-lowering and physiological effects on human health. The quantities of phytosterols in vegetable oils have been used for the classification and assessment of their quality (Rabrenovic et al., 2014; Kostadinovic Velickovska et al., 2015). The cultivation and environmental conditions influence the concentration of phytosterols. Based on the position of the double bond in the ring, phytosterols could be classified as $\Delta 5$ - and $\Delta 7$-sterols. Most species contain dominant $\Delta 5$-sterols, while $\Delta 7$-sterols are characteristic of only a few plant species and are specific bioactive compounds to pumpkin seed (Cucurbitaceae) oil (Rabrenovic et al., 2014). The phytosterol profile of the PSOs is given in Table 2 and regression analyses were also performed. There was a good correlation between the concentration of phytosterol bioactive compounds and detector intensities. Regression analysis between $\mathrm{R}^{2}=0.9740$ and 0.9990 values were indicated as satisfactory correlations for phytosterols. As can be seen in Table 2, $\Delta 7,22,25$-stigmastatrienol was the major phytosterol in the seed oils ranging from $28.3 \pm 0.1$ to $31.6 \pm 0.3 \mathrm{mg} / 100 \mathrm{~g}$ of the total phytosterol contents. Spinasterol together with $\beta$-sitosterol were the second-most abundant phytosterol, showing $42.4 \pm 2.5-47.20 \pm 2.1 \mathrm{~g} / 100 \mathrm{~g}$ of total phytosterols. They were followed by $\Delta 7$-stigmasterol with 15.1 $\pm 0.1-17.1 \pm 0.6 \mathrm{~g} / 100 \mathrm{~g}, \Delta 7,25$-stigmastadienol with $4.9 \pm 0.2-5.9 \pm 0.4 \mathrm{~g} / 100 \mathrm{~g}$, and $\Delta 7$-avenasterol with $3.20 \pm 0.1-4.00 \pm 0.3 \mathrm{~g} / 100 \mathrm{~g}$ of total phytosterols. Significantly higher contents of total phytosterols were determined and total phytosterol contents for the PSO samples which ranged from $782.1 \pm 9.7$ to $805.2 \pm 11.3 \mathrm{mg} / 100 \mathrm{~g}$ oil. Total phytosterol content in the studied samples is significantly higher than the data reported in the literature (Rabrenovic et al., 2014; Kostadinovic Velickovska et al., 2015). Thus, the high total phytosterol contents in the PSO samples from different regions of Turkey may also be related to the species of pumpkin, although the techniques used for oil extraction from seeds and the isolation procedure of phytosterols from oil may also considerably influence data.

Squalene is a natural acyclic compound produced by plant sources (mainly vegetable oils) and shark liver oils. This bioactive compound has been recommended to be an essential part of the human diet as it may be an inhibitive component that protects humans from several diseases (Ryan et al., 2007). The obtained results for the content of squalene in cold-pressed PSO samples are given in Table 2. The squalene content in the samples ranged from $591.3 \pm 10.6$ to $632.5 \pm 11.4 \mathrm{mg} / 100 \mathrm{~g}$ oil. These results are in good agreement with previously reported data for seed oils from different pumpkin cultivars (Rabrenovic et al., 2014). Differences among the contents of squalene could be attributed to the applied temperature, oil extraction procedure, and seed origin. Thus, the high content of squalene compounds contributes to the significant nutritional and therapeutic value of the cold-pressed PSOs from different regions of Turkey.

TABLE 2. Composition of phytosterols ( $\mathrm{g} / 100 \mathrm{~g}$ of total phytosterols), total phytosterol contents ( $\mathrm{mg} / 100 \mathrm{~g}$ of oil) and squalene contents (mg/100 g of oil) of the cold-pressed pumpkin seed (Cucurbita pepo L.) oils.

\begin{tabular}{lccccccc}
\hline & Squalene & $\begin{array}{c}\text { Spinasterol + } \\
\boldsymbol{\beta - s i t o s t e r o l}^{*}\end{array}$ & $\begin{array}{c}\Delta \mathbf{\Delta 7 , 2 2 , 2 5 -} \\
\text { stigmastatrienol }\end{array}$ & $\begin{array}{c}\Delta \mathbf{\Delta 7 , 2 5 -} \\
\text { stigmastadienol }\end{array}$ & $\begin{array}{c}\Delta 7- \\
\text { stigmasterol }\end{array}$ & $\begin{array}{c}\Delta 7- \\
\text { avenasterol }\end{array}$ & $\begin{array}{c}\text { Total } \\
\text { phytosterols }\end{array}$ \\
\hline $\begin{array}{l}\text { Celtik } \\
\text { PSO-Konya }\end{array}$ & $632.5 \pm 11.4$ & $42.4 \pm 2.5$ & $31.6 \pm 0.3$ & $5.7 \pm 0.1$ & $16.3 \pm 0.4$ & $4.0 \pm 0.3$ & $795.1 \pm 10.1$ \\
$\begin{array}{l}\text { Cumra } \\
\text { PSO-Konya }\end{array}$ & $597.2 \pm 13.5$ & $46.1 \pm 2.8$ & $28.7 \pm 0.7$ & $4.9 \pm 0.2$ & $17.1 \pm 0.6$ & $3.2 \pm 0.1$ & $805.2 \pm 11.3$ \\
$\begin{array}{l}\text { Iceri Cumra } \\
\text { PSO-Konya }\end{array}$ & $602.1 \pm 16.1$ & $44.9 \pm 1.7$ & $30.8 \pm 0.5$ & $5.3 \pm 0.2$ & $15.2 \pm 0.5$ & $3.8 \pm 0.1$ & $782.1 \pm 9.7$ \\
$\begin{array}{l}\text { Polath } \\
\text { PSO-Ankara }\end{array}$ & $591.3 \pm 10.6$ & $47.20 \pm 2.1$ & $28.3 \pm 0.1$ & $5.9 \pm 0.4$ & $15.1 \pm 0.1$ & $3.5 \pm 0.2$ & $790.7 \pm 12.4$ \\
\hline
\end{tabular}

* Predictable ratio spinasterol/ $\beta$-sitosterol 1:1.3 according to intensity of ion currents of molecular ions.

Results are reported as mean value \pm standard deviation of three replicate analyses $(n=3)$

Abbreviations: nd, not determined; PSO, pumpkin seed oil. 


\subsection{Tocol profiles}

Tocols are very significant non-glyceride ingredients of vegetable oils. Tocols represent a family of tocopherols $(\alpha-, \beta-, \gamma-$, and $\delta$-T) and tocotrienols $(\alpha-, \beta-, \gamma-$, and $\delta$-TT) and natural lipophilic antioxidants mainly found in vegetable oils. They are believed to be primary chain-breaking antioxidants in free radical chain reactions or in converting lipid radicals to more stable products, therefore improving the antioxidant potentials of oils. Due to their role in the protection against the oxidative deterioration of PUFAs, the content and profile of tocol isomers in vegetable oil are exceptionally important. Tocols have also been associated with the reduction of heart disease, delay of Alzheimer and prevention of cancer diseases (Mariod et al., 2009). Table 3 presents the tocol profile and content of cold pressed PSOs from central Anatolia region of Turkey. As can be seen in Table 3, significantly high amount of tocols were determined and total contents for the studied oil samples ranged from $94.29 \pm 0.34 \mathrm{mg} / 100 \mathrm{~g}$ oil to $97.79 \pm 0.76 \mathrm{mg} / 100 \mathrm{~g}$ oil. The amounts of tocols are higher than other reports and, in mentioned studies the maximum contents of tocols were detected as $70.90 \mathrm{mg} / 100 \mathrm{~g}$ oil, $35.10 \mathrm{mg} / 100 \mathrm{~g}$ oil, and $77.05 \mathrm{mg} / 100 \mathrm{~g}$ oil in pumpkin (Cucurbita pepo L.) seed oils, respectively (Stevenson et al., 2007; Nederal et al., 2012; Siger et al., 2008). The contents of these natural antioxidants in vegetable oils depends on a number of factors, such as variety characteristics, the kind of oil, extraction process, and they are possibly managed by the content of unsaturated FAs. The content of tocols in oils is also significantly affected by the processing conditions of the oil production (Rabrenovic et al., 2014).

In all the analyzed PSO samples, $\alpha-\mathrm{T}, \beta-\mathrm{T}, \gamma-\mathrm{T}$, $\beta$-TT and $\gamma$-TT isomers were identified, and $\alpha$-TT isomers were detected only in Celtik-Konya and Polatl-Ankara PSO samples (Figure 1). As is well known, the $\gamma$ - and $\delta$-tocol isomers possess a much higher antioxidant activity than the $\alpha$ - and $\beta$ - isomers; however, $\alpha$-tocol is considered to have a higher vitamin effectiveness than other tocol isomers
(Nederal et al., 2012). As can be seen in Figure 1, $\beta$-T was identified as the major tocol isomer in all the varieties, and its contents ranged from 83.00 \pm 0.38 to $86.23 \pm 0.87 \mathrm{mg} / 100 \mathrm{~g}$ oil, while the other tocol isomers were present in relatively lower quantities. The amounts of $\alpha$-tocopherol detected in the PSOs ranged from $3.66 \pm 0.03$ to $4.39 \pm 0.04 \mathrm{mg} / 100$ $\mathrm{g}$ oil.Thus, the obtained results demonstrated that the studied PSO samples were good sources of $\alpha-$, $\beta$ - and $\gamma$-tocols.

\subsection{Phenolic acid and carotenoid profiles}

Phenolic acids are known as minor antioxidant constituents, and play a determinant role due to their characteristics such as flavor, quality and resistance against the oxidation process (Nyam et al., 2009). Common vegetable oils contain different kinds and contents of phenolic acids, and data about the phenolics in cold-pressed oils are very rare in the literature. In this research, six phenolic acids; protocatechuic acid, caffeic acid, syringic acid, vanillic acid, $p$-coumaric acid, and ferulic acid were identified. The chromatogram obtained from the analysis of a standard mixture of 27 phenolic acids at 280 $\mathrm{nm}$, is illustrated in Figure 2. The concentration of the detected phenolic acids in the cold-pressed PSOs is given in Table 4 and regression analyses were also performed. There was a good correlation between the concentration of phenolic bioactive compounds and detector intensities. Values for the regression analysis between $\mathrm{R}^{2}=0.9510$ and 0.9950 are indicated as satisfactory correlations for phenolics.

As can be seen in Figure 2, the proposed method permits the baseline separation for all components including quercetin glycosides, hydroxybenzoic acids, hydroxycinnamic acids, flavanol monomers, dimers, and phloridzin. The obtained results showed that syringic acid (7.62 $\pm 0.13-8.03 \pm 0.16 \mathrm{mg} / 100 \mathrm{~g}$ oil) was the predominant acid in all the samples, followed by ferulic acid (4.72 $\pm 0.22-5.17 \pm 0.38 \mathrm{mg} / 100 \mathrm{~g}$ oil). CumraKonya cold-pressed PSO sample had the highest amount of phenolic acids $(23.98 \pm 0.46 \mathrm{mg} / 100 \mathrm{~g}$

TABLE 3. Tocol profile of the cold-pressed pumpkin seed (Cucurbita pepo L.) oils, mg/ $100 \mathrm{~g}$ oil.

\begin{tabular}{lccccccccc}
\hline & $\boldsymbol{\alpha}-\boldsymbol{T}$ & $\boldsymbol{\beta}-\boldsymbol{T}$ & $\boldsymbol{\gamma}-\boldsymbol{T}$ & $\boldsymbol{\delta}-\boldsymbol{T}$ & $\boldsymbol{\alpha}-\boldsymbol{T} \boldsymbol{T}$ & $\boldsymbol{\beta}-\boldsymbol{T} \boldsymbol{T}$ & $\boldsymbol{\gamma}-\boldsymbol{T} \boldsymbol{T}$ & $\boldsymbol{\delta}-\boldsymbol{T} \boldsymbol{T}$ & total tocol \\
\hline $\begin{array}{l}\text { Celtik } \\
\text { PSO-Konya }\end{array}$ & $3.96 \pm 0.12$ & $85.88 \pm 0.71$ & $3.23 \pm 0.11$ & nd & $0.35 \pm 0.10$ & $0.21 \pm 0.02$ & $2.82 \pm 0.07$ & nd & $\mathbf{9 6 . 4 5} \pm \mathbf{0 . 5 3}$ \\
$\begin{array}{l}\text { Cumra } \\
\text { PSO-Konya }\end{array}$ & $4.39 \pm 0.04$ & $86.23 \pm 0.87$ & $4.27 \pm 0.11$ & nd & nd & $0.21 \pm 0.05$ & $2.69 \pm 0.03$ & nd & $\mathbf{9 7 . 7 9} \pm \mathbf{0 . 7 6}$ \\
$\begin{array}{l}\text { Iceri Cumra } \\
\text { PSO-Konya }\end{array}$ & $3.66 \pm 0.03$ & $83.00 \pm 0.38$ & $3.43 \pm 0.02$ & nd & nd & $0.78 \pm 0.02$ & $3.42 \pm 0.05$ & nd & $\mathbf{9 4 . 2 9} \pm \mathbf{0 . 3 4}$ \\
$\begin{array}{l}\text { Polatl } \\
\text { PSO-Ankara }\end{array}$ & $4.07 \pm 0.02$ & $85.35 \pm 0.22$ & $3.44 \pm 0.01$ & nd & $0.43 \pm 0.04$ & $0.27 \pm 0.01$ & $2.88 \pm 0.01$ & nd & $\mathbf{9 6 . 4 4} \pm \mathbf{0 . 1 6}$ \\
\hline
\end{tabular}

Results are reported as mean value \pm standard deviation of three replicate analyses $(n=3)$

Abbreviations: nd, not determined; T, tocopherol; TT, tocotrienol; $\alpha$, alpha; $\beta$, beta; $\gamma$, gamma; $\delta$, sigma; PSO, pumpkin seed oil. 




FIGURE 1. NP-HPLC/FLD chromatogram of the cold-pressed pumpkin seed (Cucurbita pepo L.) oil from the Cumra region for tocol analysis.

oil) followed by Iceri Cumra-Konya cold-pressed PSO sample (23.66 $\pm 0.34 \mathrm{mg} / 100 \mathrm{~g}$ oil). Minor amounts of phenolic acids such as protocatechuic acid, caffeic acid, vanillic acid and $p$-coumaric acids were also detected. The differences in the amounts of phenolic compounds may occur due to differences in the extraction methods, origin of seeds, environmental conditions and the treatments applied to the seeds before extraction (Alothman et al., 2009).

The carotenoid composition ( $\beta$-carotene, lutein, zeaxanthin and cryptoxanthin) of the cold-pressed PSOs is alsogiven in Table 4. Zeaxanthin was the major carotenoid pigment present in all the studied PSOs with a range of $2.65 \pm 0.05-2.91 \pm 0.03 \mathrm{mg} / 100 \mathrm{~g}$ oil. The Cumra-Konya PSO sample contained the highest amount of total carotenoids $(7.60 \pm 0.03 \mathrm{mg} / 100$ g oil), followed by the Iceri cumra-Konya (7.21 \pm 0.05 $\mathrm{mg} / 100 \mathrm{~g}$ oil) PSO samples. This PSOs also had the highest $\beta$-carotene content of $0.54 \pm 0.02$ to $0.60 \pm 0.02$ $\mathrm{mg} / 100 \mathrm{~g}$ oil, among all the studied oil samples which was much higher than that observed in cold-pressed seed oils (0.01-0.24 mg/100 g), and also much higher than that of refined oils (0.01-0.12 mg/100 g) (Parry et al., 2006). The obtained results demonstrated that different contents and profiles of carotenoids are influenced by the genetics and phase of seed maturation, and also by oil extraction and storage conditions. Thus, these data suggest that the studied cold-pressed PSOs may serve as dietary sources of carotenoids, especially zeaxanthin (Parry et al., 2006).

\subsection{Antioxidant activity data}

Phenolic compounds which have unique chemical characteristics posing low-energy radicals through stable hybrids are thought to be good antioxidants for foodstuffs. They have also proven to possess important roles in their quality and nutritional values. Natural oils contain more polar compounds that have mainly phenolic characteristics. These phenolics are secondary components and represent only a minor fraction of the oil. Phenolic compounds may also exert high biological activity far beyond their antioxidant properties, so the determination of phenolic compounds in vegetable oil is of great interest (Latif et al., 2011). As can be seen in Table 5, the content of total phenolic compounds (TPCs) in cold-pressed PSOs is in the range of 3.96 $\pm 0.13-5.82 \pm 0.15 \mathrm{mg} \mathrm{GAE} / 100 \mathrm{~g}$. The content of TPCs are in the following order: $4.32 \pm 0.09 \mathrm{mg}$ GAE/100 g, $5.82 \pm 0.15 \mathrm{mg}$ GAE/100 g, $3.96 \pm 0.13$ $\mathrm{mg} \mathrm{GAE} / 100 \mathrm{~g}, 4.32 \pm 0.12 \mathrm{mg}$ GAE$/ 100 \mathrm{~g}$ for PSOs from Celtik-Konya, Cumra-Konya, Iceri CumraKonya and Polatli-Ankara, respectively. Values from the regression analyses with $\mathrm{R}^{2}=0.9944,0.9933$ and 0.9972 are indicated as satisfactory correlations for total phenolic compounds, free radical-scavenging and antioxidant activity analyses, respectively. There was also a directly relative correlation between TPCs and total tocol content. It is clear that Cumra-KonyaPSO is the richest cold-pressed oil in terms of both the TPCs and tocol content (Tables 3 




FIGURE 2. RP-HPLC/DAD chromatogram of the standard mixture of phenolic acids.

TABLE 4. Phenolic acid and carotenoid compositions of the cold-pressed pumpkin seed (Cucurbita pepo L.) oils.

\begin{tabular}{lcccc}
\hline & Celtik PSO-Konya & Cumra PSO-Konya & Iceri Cumra PSO -Konya & Polatlı PSO-Ankara \\
\hline Protocatechuic acid & $1.78 \pm 0.25$ & $2.07 \pm 0.18$ & $1.84 \pm 0.22$ & $1.56 \pm 0.24$ \\
Caffeic acid & $3.75 \pm 0.31$ & $3.68 \pm 0.60$ & $3.83 \pm 0.44$ & $3.41 \pm 0.33$ \\
Syringic acid & $8.03 \pm 0.16$ & $7.92 \pm 0.21$ & $7.62 \pm 0.13$ & $7.85 \pm 0.11$ \\
Vanillic acid & $2.44 \pm 0.37$ & $2.75 \pm 0.41$ & $2.54 \pm 0.19$ & $2.61 \pm 0.23$ \\
$\boldsymbol{p}$-coumaric acid & $2.48 \pm 0.87$ & $2.59 \pm 0.31$ & $2.66 \pm 0.53$ & $2.58 \pm 0.27$ \\
Ferulic acid & $5.04 \pm 0.26$ & $4.97 \pm 0.18$ & $5.17 \pm 0.38$ & $4.72 \pm 0.22$ \\
$\boldsymbol{\beta}$-Carotene & $0.59 \pm 0.01$ & $0.60 \pm 0.02$ & $0.55 \pm 0.01$ & $0.54 \pm 0.02$ \\
Lutein & $0.03 \pm 0.001$ & $0.03 \pm 0.001$ & $0.02 \pm 0.001$ & $0.02 \pm 0.001$ \\
Zeaxanthin & $2.74 \pm 0.06$ & $2.91 \pm 0.03$ & $2.73 \pm 0.02$ & $2.65 \pm 0.05$ \\
Cryptoxanthin & $0.49 \pm 0.01$ & $0.46 \pm 0.01$ & $0.47 \pm 0.01$ & $0.43 \pm 0.01$ \\
Total carotenoids, $\boldsymbol{\mu m o l} / \mathbf{k g}$ & $7.06 \pm 0.02$ & $7.60 \pm 0.03$ & $7.21 \pm 0.05$ & $6.95 \pm 0.03$ \\
\hline
\end{tabular}

Results are reported as mean value \pm standard deviation of three replicate analyses $(n=3)$

Abbreviations: PSO, pumpkin seed oil.

and 5). According to the literature, the content of total phenolic compounds in oil is mainly related to the oil from roasted pumpkin seeds, and is reported to range from 0.28 to $2.46 \mathrm{mg}$ GAE/100 $\mathrm{g}$ (Tuberoso et al., 2007; Siger et al., 2008). Andjelkovic et al., (2010) reported the contents of phenolics in PSO samples in a range from 2.47 to $5.09 \mathrm{mg}$ GAE/100 g. Also, higher contents of phenolic compounds in a range from 7.33 to $128.84 \mathrm{mg}$ GAE/100 $\mathrm{g}$ were reported by Jiao et al., (2014).
In order to identify the antioxidant activity of the studied pumpkin seed samples, 2,2-diphenyl1-picrylhydrazyl (DPPH) radical-scavenging activities of oil extracts were determined. The values of free radical-scavenging activity were detected in the following order; $5.70 \pm 0.13 \mathrm{mg}$ GAE/100 g, 7.35 $\pm 0.15 \mathrm{mg}$ GAE$/ 100 \mathrm{~g}, 6.32 \pm 0.11 \mathrm{mg}$ GAE/100 g, $6.67 \pm 0.14 \mathrm{mg}$ GAE/100 $\mathrm{g}$ for the seed oils from Celtik-Konya, Cumra-Konya, Iceri Cumra-Konya and Polatl1-Ankara, respectively (Table 5). As 
TABLE 5. Total phenolic compounds, free radical scavenging activity and antioxidant activity of the cold-pressed pumpkin seed (Cucurbita pepo L.) oils, mg GAE/ $100 \mathrm{~g}$.

\begin{tabular}{lccc}
\hline & Total phenolic compound content & Free radical scavenging activity & Total antioxidant activity \\
\hline Celtik PSO-Konya & $4.32 \pm 0.09$ & $5.70 \pm 0.13$ & $27.78 \pm 1.12$ \\
Cumra PSO-Konya & $5.82 \pm 0.15$ & $7.35 \pm 0.15$ & $38.89 \pm 1.41$ \\
Iceri Cumra PSO-Konya & $3.96 \pm 0.13$ & $6.32 \pm 0.11$ & $26.67 \pm 0.97$ \\
Polatlı PSO-Ankara & $4.32 \pm 0.12$ & $6.67 \pm 0.14$ & $31.11 \pm 1.03$
\end{tabular}

Results are reported as mean value \pm standard deviation of three replicate analyses $(n=3)$

Abbreviations: GAE, gallic acid equivalents; PSO, pumpkin seed oil.

shown in Table 5, the extract of Cumra-KonyaPSO exhibited superior antioxidant activity $(7.35 \pm 0.15$ mg GAE/100 g) compared with other oil extracts. As expected, Cumra-Konya PSO exhibited a higher antioxidant activity than others, which can be substantially explained by the higher tocol, carotenoidand phenolic contents of this oil than that in other studied oils. In fact, the antioxidant potential of vegetable oils is directly related to their tocol, carotenoid and phenolic compound contents (Fruhwirth et al., 2003; Latif, 2011).

The total antioxidant activities of the studied PSOs were determined at $695 \mathrm{~nm}$. In the studied PSOs, the total antioxidant activity values were in the range of $26.67 \pm 0.97-38.89 \pm 1.41 \mathrm{mg}$ GAE$/ 100 \mathrm{~g}$. The lowest value for total antioxidant activity was determined for the Iceri Cumra-Konya PSO sample (26.67 $\pm 0.97 \mathrm{mg} \mathrm{GAE} / 100 \mathrm{~g}$ ), whereas, the CumraKonya sample had the highest value $(38.89 \pm 1.41$ $\mathrm{mg}$ GAE/100 g). In view of the oxidative stability of vegetable oils, the presence of natural bioactive compounds with anti-oxidative activity is a vital factor. Tuberoso et al., (2007) deduced that the changeability of the relationship between the antioxidant activity and profile of the seed oils could be characteristic of the differences in the contents of bioactive compound of the oils and their interactions. Frushwirth et al., (2003) also reported that PSO samples have $59 \%$ of their antioxidant activity due to the phenolic compounds, and $41 \%$ to the tocols. Similar to the other antioxidant activity data, Cumra-Konya seed oil exhibited higher antioxidant activity than others. As known from previous studies; the cultivar, genetic factors, extraction system, production and storage conditions of seed oils are quite critical factors for the contents of antioxidant compounds (Nawirska-Olszanska et al., 2013). Thus, the differences in antioxidant activity data of the PSOs in this study are predicted to be mainly derived from their cultivar variations and genetic factors.

\section{CONCLUSIONS}

In the present study, the cold-pressed oils from pumpkin (Cucurbita pepo L.) seeds cultivated in different central Anatolia regions of Turkey were analyzed and they have shown high contents of bioactive compounds. High contents of phytosterols, squalene, tocols, phenolic acids, carotenoids and phenolic bioactives, and high values of free radical scavenging as well as antioxidant activity make these oils nutritionally and medicinally valuable. The presence of essential fatty acids and well-balanced fatty acid profiles (ratios of SFAs, MUFAs and PUFAs) of PSOs can be an indicator of their stability and nutritional quality. High levels of bioactives detected in these oils could contribute to stability toward oxidation reactions and provide highquality oil used as edible oil. Therefore, the content of bioactive compound for the studied PSOs can be an indicator of its stability and nutritional quality. Also, the screw-pressing process used in this study involves no organic solvent, which results in high quality cold-pressed PSO that is chemically-contaminant free.

\section{ACKNOWLEDGMENT}

The present study was supported by Karamanoglu Mehmetbey University (Karaman, Turkey) Scientific Research Project Center with 05-YL-15 and 18-M-17 project numbers. The authors wish to thank K.M.U. Scientific Research Project Center for the facilities provided.

\section{ABBREVIATIONS}

ANOVA: analysis of variance; AOCS: American oil chemical society; FA: fatty acids; GAE: gallic acid equivalent; GC: gas chromatography; GC-FID: gas chromatography-flame ionization detector; GC-MS: gas chromatography-mass spectroscopy; HPLC: high performance liquid chromatography; HPLCFLD: high performance liquid chromatographyfluorescence detector; HPLC-DAD: high performance liquid chromatography-diode array detector; MS: mass spectroscopy; MUFA: monounsaturated fatty acids; NP-HPLC: normal phase-high performance liquid chromatograph; RP-HPLC: reversed phasehigh performance liquid chromatograph; PSO: pumpkin seed oil; PUFA: polyunsaturated fatty acids; SFA: saturated fatty acids; T: tocopherol; TT: tocotrienol; UV-Vis: ultraviolet-visible 


\section{REFERENCES}

Alothman M, Bhat R, Karim AA. 2009. Antioxidant capacity and phenolic content of selected tropical fruits from Malaysia, extracted with different solvents. Food Chem. 115, 785-788. https://doi.org/10.1016/j.foodchem.2008.12.005

Andjelkovic M, Camp JV, Trawka A, Verhe R. 2010. Phenolic compounds and some quality parameters of pumpkin seed oil. Eur. J. Lipid Sci. Technol. 112, 208-217. https://doi. org/10.1002/ejlt.200900021

Arslan FN, Kara H. 2016. Fully Automated Three-Dimensional Column-Switching SPE-FIA-HPLC System for the Characterization of Lipids by a Single Injection: Part I. Instrumental Design and Chemometric Approach to Assess the Effect of Experimental Settings on the Response of ELSD. J. Am. Oil Chem. Soc. 93, 11-26. https://doi. org/10.1007/s11746-015-2750-0

Arslan FN, Sapcı AN, Duru F, Kara H. 2017. A study on monitoring of frying performance and oxidative stability of cottonseed and palm oil blends in comparison with original oils. Int. J. Food Prop. 20, 704-717. https://doi.org/10.1080/ 10942912.2016.1177544

Feng-Lin S, Ren-You G, Yuan Z, Qin X, Lei K, Hua-Bin L. 2010. Total Phenolic Contents and Antioxidant Capacities of Selected Chinese Medicinal Plants. Int. J. Mol. Sci. 11, 2362-2372. https://doi.org/10.3390/ijms11062362

Fruhwirth GO, Hermetter A. 2007. Seeds and oil of the Styrian oil pumpkin: Components and biological activities. Eur. J. Lipid Sci. Technol. 109, 1128-1140. https://doi.org/10.1002/ ejlt. 200700105

Fruhwirth GO, Wenzl T, El-Toukhy R, Wagner FS, Hermetter A. 2003. Fluorescence screening of antioxidant capacity in pumpkin seed oils and other natural oils. Eur. J. Lipid Sci. Technol. 105, 266-274. https://doi.org/10.1002/ ejlt.200390055

Gu Q, David F, Lynen F, Vanormelingen P, Vyverman W, Rumpel K, Xu G, Pat S. 2011. Evaluation of ionic liquid stationary phases for one dimensional gas chromatography-mass spectrometry and comprehensive two dimensional gas chromatographic analyses of fatty acids in marine biota. J. Chromatogr. A 1218, 3056-3063. https:// doi.org/10.1016/j.chroma.2011.03.011

Jafari M, Goli SAH, Rahimmalek M. 2012. The chemical composition of the seeds of Iranian pumpkin cultivars and physicochemical characteristics of the oil extract. Eur. J. Lipid Sci. Technol. 114, 161-167. https://doi.org/10.1002/ ejlt.201100102

Jiao J, Li ZG, Gai QY, Li XJ, Wei FY, Fu YJ, Wei M. 2014 Microwave-assisted aqueous enzymatic extraction of oil from pumpkin seeds and evaluation of its physicochemical properties, fatty acid compositions and antioxidant activities. Food Chem. 147, 17-24. https://doi.org/10.1016/j. foodchem.2013.09.079

Kostadinovic Velickovska S, Bruhl L, Mitrev S, Mirhosseini H, Matthaus M. 2015. Quality evaluation of coldpressed edible oils from Macedonia. Eur. J. Lipid Sci. Technol. 117, 2023-2035. https://doi.org/10.1002/ejlt. 201400623

Kulaitiene J, Jariene E, Danilcenko H, Kita A, Venskutoniene E. 2016. Oil pumpkins seeds and their quality. Pol. J. Food Nutr. Sci. 4, 349-352.

Latif S, Anwar S. 2011. Aqueous enzymatic sesame oil and protein extraction. Food Chem. 125, 679-684. https://doi. org/10.1016/j.foodchem.2010.09.064

Mateos R, Espartero JL, Trujillo M, Ríos JJ, León-Camacho M, Alcudia F, Arturo C. 2001. Determination of Phenols, Flavones, and Lignans in Virgin Olive Oils by Solid-Phase Extraction and High-Performance Liquid Chromatography with Diode Array Ultraviolet Detection. J. Agric. Food Chem. 49, 2185-2192. https:// doi.org/10.1021/jf0013205
Mariod AA, Yousif MA, Matthaüs B, Khaleel G, Siddig A, Gabra AM, Siddig IA. 2009. A Comparative Study of the Properties of Six Sudanese Cucurbit Seeds and Seed Oils. J. Am. Oil Chem. Soc. 86, 1181-1188. https://doi. org/10.1007/s11746-009-1459-3

Molyneux P. 2004. The use of the stable free radical diphenylpicryl- hydrazyl (DPPH) for estimating antioxidant activity. Songklanakarin J. Sci. Technol. 26, 211-219.

Nederal S, Skevin D, Kraljic K, Obranovic M, Papesa SI, Bataljaku A. 2012. Chemical composition and oxidative stability of roasted and cold pressed pumpkin seed oils. J. Am. Oil Chem. Soc. 89, 1763-1770. https://doi.org/10.1007/s11746-012-2076-0

Nederal S, Petrovic M, Vincek D, Pukec D, Skevin D, Kraljic K, Obranovic M. 2014. Variance of quality parameters and fatty acid composition in pumpkin seed oil during three crop seasons. Ind. Crops Prod. 60, 15-21. https://doi. org/10.1016/j.indcrop.2014.05.044

Nyam KL, Tan V, Lai V, Long K, Che Man YB. 2009. Physicochemical properties and bioactive compounds of selected seed oils. LWT-Food Sci. Technol. 42, 1396-1403. https://doi.org/10.1016/j.lwt.2009.03.006

Nawirska-Olszanska A, Kita A, Biesiada A, Sokół-Łetowska A, Kucharska AZ. 2013. Characteristics of antioxidant activity and composition of pumpkin seed oils in 12 cultivars. Food Chem. 139, 155-161. https://doi.org/10.1016/j. foodchem.2013.02.009

Omah BD, Ladet S, Godfrey DV, Liang J, Girard B. 2000. Characteristics of raspberry (Rubus idaeus L.) seed oil. Food Chem. 69, 187-193. https://doi.org/10.1016/ S0308-8146(99)00260-5

Parry J, Zhigang H, Luthera M, Lan S, Kequan Z, Liangli Y. 2006. Characterization of Cold-Pressed Onion, Roasted Pumpkin, and Milk Thistle Seed Oils. J. Am. Oil Chem. Soc. 83, 847-854. https://doi.org/10.1007/ s11746-006-5036-8

Prieto P, Pineda M, Aguilar M. 1999. Spectrophotometric Quantitation of Antioxidant Capacity through the Formation of a Phosphomolybdenum Complex: Specific Application to the Determination of Vitamin E. Anal. Biochem. 269, 337341. https://doi.org/10.1006/abio.1999.4019

Rabrenovic BB, Dimic EB, Novakovic MM, Tesevic VV, Basic ZN. 2014. The most important bioactive components of cold pressed oil from different pumpkin (Cucurbita pepo L.) seeds. LWT - Food Sci. Technol. 55, 521-527. https://doi.org/10.1016/j.lwt.2013.10.019

Rezig L, Chouaibi M, Msaada K, Hamdi S. 2012. Chemical composition and profile characterisation of pumpkin (Cucurbita maxima) seed oil. Ind. Crop. Prod. 37, 82-87. https://doi.org/10.1016/j.indcrop.2011.12.004

Ryan E, Galvin K, O'Connor TP, Maguire AR, O'Brien NM. 2007. Phytosterol, Squalene, Tocopherol Content and Fatty Acid Profile of Selected Seeds, Grains, and Legumes. Plant Foods Hum. Nutr. 62, 85-91. https://doi.org/10.1007/ s11130-007-0046-8

Siger A, Nogala-Kalucka M, Lampart-Szczapa E. 2008. The content and antioxidant activity of phenolic compounds in cold-pressed plant oils. J. Food Lipids 15, 137-149. https:// doi.org/10.1111/j.1745-4522.2007.00107.x

Stevenson DG, Eller FJ, Wang L, Jay-Lin J, Wang T, Inglett GE. 2007. Oil and Tocopherol Content and Composition of Pumpkin Seed Oil in 12 Cultivars. J. Agric. Food Chem. 55, 4005-4013. https://doi.org/10.1021/jf0706979

Tuberoso CIG, Kowalczyk A, Sarritzu E, Cabras P . 2007. Determination of antioxidant compounds and antioxidant activity in commercial oil seeds for food use. Food Chem. 103, 1494-1501. https://doi.org/10.1016/j. foodchem.2006.08.014

Vujasinovic V, Djilas S, Dimic E, Romanic R, Takaci A. 2010. Shelf life of cold-pressed pumpkin (Cucurbita pepo L.) seed oil obtained with a screw press. J. Am. Oil Chem. Soc. 87, 1497-1505. https://doi.org/10.1007/s11746-010-1630-x 